\title{
ON COMMUTATORS IN MATRIX THEORY
}

\author{
GEOFFREY R. GOODSON
}

Abstract. We investigate intertwining relations arising from commutators such as $A B-B A=D$ when $A D=D A$, and $A B-B A^{T}=D$ when $A D=D A^{T}$, where $A, B$ and $D$ are $n$-by- $n$ matrices. Depending on the properties of $A$, such equations often force $D$ to be zero or at least nilpotent, and it is the properties of $D$ that we investigate. We briefly discuss the situation when $A B+B A=$ $D, A D=D A^{T}$ for $A$ normal.

Mathematics subject classification (2010): 15A18, 15A27.

Keywords and phrases: Matrix commutator, nonderogatory matrix, normal matrix.

\section{REFERENCES}

[1] G. R. Goodson, R. A. Horn And D. I. Merino, Quasi-real normal matrices and eigenvalue pairings, Linear Algebra Appl., 369 (2003), 279-294.

[2] G. R. GOODSON AND R. A. HoRn, Canonical forms for normal matrices that commute with their complex conjugate, Linear Algebra Appl., 430 (2009), 1025-1038.

[3] R. A. Horn And C. R. Johnson, Matrix Analysis, Cambridge University Press, New York, 1985.

[4] R. A. Horn And C. R. Johnson, Matrix Analysis, 2nd Edition, Cambridge University Press (to appear).

[5] R. A. Horn And C. R. Johnson, Topics in Matrix Analysis, Cambridge University Press, New York, 1991.

[6] N. JACOBSON, Rational methods in the theory of Lie algebras, Annals Math., 36 (1935), 875-881.

[7] C. R. Putnam, On normal operators in Hilbert space, Amer. J. Math., 73 (1971), 357-362.

[8] H. Shapiro, Commutators which commute with one factor, Pac. J. Math., 181 (1997), 323-336.

[9] O. TAUSSKY, The role of symmetric matrices in the study of general matrices, Linear Algebra Appl., 5 (1972), 147-154.

[10] F. Zhang, Linear Algebra: Challenging Problems for Students, The Johns Hopkins University Press (2nd Edition), 2009. 